\title{
SATISFACTION SUR VEY ON ORAL HEALTH SERVICE FOR SCHOOL CHILDREN (UKGS)
}

\author{
Hermien Nugraheni $^{\varpi 1}$, Tri Wiyatini ${ }^{2}$, Lanny Sunarjo ${ }^{3}$
}

\begin{abstract}
ABSTRAK
Pelayanan kesehatan gigi dan mulut pada anak sekolah selain dilaksanakan melalui kegiatan pokok kesehatan gigi dan mulut di Puskesmas juga diselenggarakan secara terpadu dalam bentuk program Usaha Kesehatan Gigi Sekolah (UKGS). Tujuan penelitian ini adalah menganalisis tingkat kepuasan siswa, guru UKGS, dan orangtua siswa terhadap upaya penyelenggaraan UKGS yang terdiri atas layanan : pendidikan kesehatan, layanan kesehatan dan lingkungan sekolah sehat pada sekolah dasar di wilayah kerja Puskesmas Kedungmundu Semarang.

Kualitas pelayanan UKGS harus diorientasikan pada kebutuhan klien yang dalam hal ini disebut masyarakat sekolah yang terdiri atas siswa, guru UKGS dan orangtua siswa. Penelitian ini merupakan suatu penelitian deskriptif, dengan menilai tingkat kepuasan atas layanan UKGS menggunakan Gap Analysis dan Diagram Cartesius.

Berdasarkan hasil perhitungan skor kepuasan baik pada responden siswa, guru UKGS maupun orangtua siswa, diketahui item terbaik adalah pada komponen pendidikan kesehatan, sedangkan hal-hal yang masih harus ditingkatkan ke depannya, meliputi : komponen layanan kesehatan dan pemenuhan sarana prasarana menuju lingkungan sekolah yang sehat.
\end{abstract}

Kata kunci : Kepuasan, UKGS

\begin{abstract}
Oral and dental health services for school children in addition to the main dental and oral health activities at the Puskesmas are also integrated in the form of the School Dental Health (UKGS) program. The purpose of this study is to analyze the level of satisfaction of students, UKGS's teachers, and parents to the efforts of UKGS which consists of services: health education, health service and healthy school environment at elementary school in Kedungmundu Semarang Public Health Centre working area.

The quality of the UKGS service should be oriented to the needs of the client, in this case called the school community consisting of students, UKGS's teachers and parents. This research is a descriptive study, by assessing the satisfaction level of UKGS service using Gap Analysis and Cartesius Diagram.

Based on the results of the calculation of satisfaction scores both in the student respondents, UKGS's teachers and parents, it is known that the best item is on the health education component, while the thing s that still need to be improved in the future, include: health service component and fulfillment of infrastructure to the healthy school environment.
\end{abstract}

Keywords : Satisfaction, UKGS

$\overline{1,2,3)}$ Dosen Jurusan Keperaw atan Gigi Poltekkes Kemenkes Semarang

: hermienprajoga@gmail.com 


\section{PENDAHULUAN}

Penyakit gigi dan mulut merupakan penyakit masyarakat yang dapat menyerang semua golongan umur yang bersifat progresif dan akumulatif. Dari prevalensi 10 (sepuluh) kelompok penyakit yang dikeluhkan masyarakat, penyakit gigi dan mulut menduduki urutan pertama dengan angka prevalensi $61 \%$ penduduk (Kemenkes RI, 2013).

Pelayanan kesehatan gigi dan mulut sebagai bagian integral dari pelayanan kesehatan secara keseluruhan telah menetapkan indikator status kesehatan gigi dan mulut masyarakat yang mengacu pada Global Goals for Oral Health 2020 (Kemenkes RI, 2012). Salah satu program teknis dari Departement of Noncommunicable Disease Prevention and Health Promotion yang mewadahi program kesehatan gigi dan mulut secara global adalah WHO Global Oral Health Programmem(GOHP) (Kemenkes RI, 2012). Program ini menyarankan negara-negara di dunia untuk mengembangkan kebijakan pencegahan penyakit gigi dan mulut serta promosi kesehatan gigi dan mulut. Kebijakan ini juga mendukung integrasi program kesehatan gigi dan mulut dengan program kesehatan umum. Salah satu aksi prioritas dari GOHP, khususnya untuk anak sekolah dan remaja adalah promosi kesehatan gigi di sekolah (Pratiwi dkk, 2016).

Pelayanan kesehatan gigi dan mulut pada anak sekolah selain dilaksanakan melalui kegiatan pokok kesehatan gigi dan mulut di Puskesmas juga diselenggarakan secara terpadu dengan kegiatan pokok UKS dalam bentuk program Usaha Kesehatan Gigi Sekolah (UKGS) (Kemenkes RI, 2012).

Tujuan penelitian ini adalah untuk mengetahui kepuasan masyarakat sekolah yang terdiri atas : siswa, guru pembina UKGS, dan orangtua siswa terhadap kualitas layanan UKGS.

\section{METODE PENELITIAN}

Penelitian ini merupakan penelitian observasional yang kemudian datanya dianalisis secara Frequency dan Descriptive untuk menggambarkan gap (kesenjangan) antara kepentingan/ ekspektasi dan kinerja/ kepuasan pelanggan terhadap kualitas pelayanan Usaha Kesehatan Gigi Sekolah. (Archambault, 2008) Untuk mengetahui tingkat kepuasan pelayanan pelanggan, digunakan Gap Analysis dan Diagram Cartesius (Rubaman, 2008).

Populasi penelitian ini adalah masyarakat sekolah-sekolah dasar di wilayah kerja Puskesmas Kedungmundu Kota Semarang sejumlah 31 sekolah. Sehingga responden penelitian ini meliputi : 31 orang siswa (satu orang siswa dari setiap sekolah), yang didampingi 31 orangtuanya, dan 31 orang guru Pembina UKGS.

\section{HASIL DAN PEMBAHASAN}

1. Kinerja Aktual dan Harapan Responden Siswa terhadap Layanan Usaha Kesehatan Gigi Sekolah.

Pada penelitian ini, responden diminta untuk menilai tingkat kepentingan dan kinerja UKGS dalam penyelenggaraan layanan yang meliputi : layanan pendidikan kesehatan, pelayanan kesehatan, dan lingkungan sekolah sehat. Maka didapat hasil sebagai berikut : 
Tabel 1. Analisis Kepuasan Siswa terhadap Layanan Usaha Kesehatan Gigi Sekolah

\begin{tabular}{|c|c|c|c|c|c|}
\hline Komponen & $\begin{array}{l}\text { Kualitas } \\
\text { Layanan } \\
\end{array}$ & Kategori & $\begin{array}{c}\text { Tingkat } \\
\text { Kepuasan }\end{array}$ & Kategori & $\begin{array}{c}\text { Tingkat Kesesuaian } \\
(\%)\end{array}$ \\
\hline $\begin{array}{l}\text { Pemberian pengetahuan } \\
\text { tentang kesehatan gigi dan } \\
\text { mulut }\end{array}$ & 4.65 & $\begin{array}{l}\text { Sangat } \\
\text { penting }\end{array}$ & 3.82 & Puas & 82.11 \\
\hline $\begin{array}{l}\text { Latihan atau demonstrasi } \\
\text { cara memelihara kebersihan } \\
\text { dan } \\
\text { kesehatan gigi dan mulut }\end{array}$ & 4.59 & $\begin{array}{l}\text { Sangat } \\
\text { penting }\end{array}$ & 3.77 & Puas & 82.24 \\
\hline Sikat gigi bersama di sekolah & 4.56 & $\begin{array}{l}\text { Sangat } \\
\text { penting }\end{array}$ & 3.87 & Puas & 84.90 \\
\hline $\begin{array}{l}\text { Penyuluhan kesehatan gigi } \\
\text { dan mulut perorangan }\end{array}$ & 4.62 & $\begin{array}{l}\text { Sangat } \\
\text { penting }\end{array}$ & 3.84 & Puas & 83.13 \\
\hline $\begin{array}{l}\text { Pemeriksaan dan penjaringan } \\
\text { kesehatan gigi dan mulut } \\
\text { peserta } \\
\text { didik }\end{array}$ & 4.58 & $\begin{array}{l}\text { Sangat } \\
\text { penting }\end{array}$ & 3.83 & Puas & 83.55 \\
\hline $\begin{array}{l}\text { Perawatan kesehatan gigi } \\
\text { dan mulut }\end{array}$ & 4.57 & $\begin{array}{l}\text { Sangat } \\
\text { penting }\end{array}$ & 3.77 & Puas & 82.55 \\
\hline $\begin{array}{l}\text { Rujukan kesehatan gigi dan } \\
\text { mulut }\end{array}$ & 4.57 & $\begin{array}{l}\text { Sangat } \\
\text { penting }\end{array}$ & 3.62 & Puas & 79.09 \\
\hline $\begin{array}{lrr}\text { Sarana } & \text { prasarana } & \text { dan } \\
\text { lingkungan } & \text { sekolah } & \text { sehat } \\
\text { memadai } & & \end{array}$ & 4.55 & $\begin{array}{l}\text { Sangat } \\
\text { penting }\end{array}$ & 3.51 & Puas & 77.31 \\
\hline rata-rata & 4.59 & $\begin{array}{l}\text { Sangat } \\
\text { penting }\end{array}$ & 3.75 & Puas & 81.87 \\
\hline
\end{tabular}

Selanjutnya nilai rata-rata tingkat kepentingan dan kinerja tersebut dianalisis pada Importance-Performance Matrix, yang mana sumbu x mewakili persepsi sedangkan sumbu y mewakili harapan. Maka didapat hasil berupa gambar sebagai berikut :

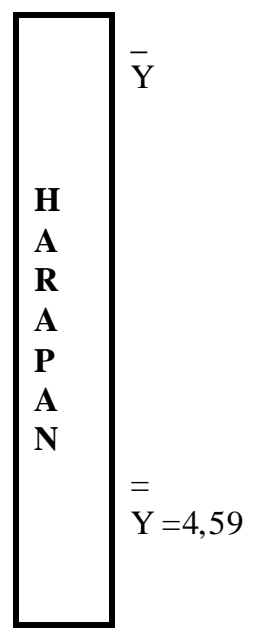

\begin{tabular}{|c|c|c|}
\hline \multicolumn{2}{|c|}{$\begin{array}{l}\text { A. Prioritas Utama } \\
\text { 1. Perawatan kesehatan gigi dan } \\
\text { mu lut } \\
\text { 2. Sarana prasarana dan } \\
\text { lingkungan sekolah sehat } \\
\text { memadai }\end{array}$} & $\begin{array}{ll}\text { B. } & \text { Pertahankan Prestasi } \\
\text { 1. Pemberian pengetahuan tentang } \\
\text { kesehatan gigi dan mulut } \\
\text { 2. Latihan atau demonstrasi cara } \\
\text { memelihara kebersihan dan } \\
\text { kesehatan gigi dan mulut } \\
\text { 3. Sikat gigi bersama di sekolah } \\
\text { 4. Penyuluhan kesehatan gigi dan } \\
\text { mulut perorangan }\end{array}$ \\
\hline \multirow[t]{3}{*}{$\begin{array}{c}\text { C. Prioritas Rendah } \\
\text { Layanan rujukan }\end{array}$} & & D. Berlebihan \\
\hline & $\begin{array}{l}= \\
X=3,75\end{array}$ & \\
\hline & & PELAKSANAAN KINERJA \\
\hline
\end{tabular}

Gambar 1. Diagram Kartesius dari Kualitas Layanan dan Kinerja/Kepuasan Siswa terhadap Layanan Usaha Kesehatan Gigi Sekolah 
Berdasarkan hasil perhitungan skor kepuasan siswa yang telah dilakukan dapat diketahui beberapa item terbaik yaitu : pemberian pengetahuan tentang kesehatan gigi dan mulut, latihan atau demonstrasi cara memelihara kebersihan dan kesehatan gigi dan mulut, sikat gigi bersama di sekolah dan penyuluhan kesehatan gigi dan mulut perorangan.

Dengan analisis Importance Performance Analysis (IPA) maka dapat diketahui bahwa hal yang harus ditingkatkan ke depannya, meliputi : perawatan kesehatan gigi dan mulut serta sarana prasarana dan lingkungan sekolah sehat yang memadai.

2. Kinerja Aktual dan Harapan Responden Guru UKGS terhadap Layanan Usaha Kesehatan Gigi Sekolah.
Pada penelitian ini, responden diminta untuk menilai tingkat kepentingan dan kinerja UKGS yang meliputi : Pelatihan kepada guru Pembina UKGS dan dokter kecil tentang pengetahuan kesehatan gigi dan mulut secara terintegrasi, pendidikan kesehatan gigi dilaksanakan oleh guru pembina UKGS sesuai dengan kurikulum yang berlaku, pencegahan penyakit gigi dan mulut dengan melaksanakan kegiatan sikat gigi bersama, pengobatan darurat untuk menghilangkan rasa sakit oleh guru dan rujukan bagi yang memerlukan. Maka didapat hasil sebagai berikut :

Tabel 2. Analis is Kepuasan Guru UKGS terhadap Layanan Usaha Kesehatan Gigi Sekolah

\begin{tabular}{|c|c|c|c|c|c|}
\hline Komponen & $\begin{array}{l}\text { Kualitas } \\
\text { Layanan }\end{array}$ & Kateg ori & $\begin{array}{c}\text { Tingkat } \\
\text { Kepuasan }\end{array}$ & Kateg ori & $\begin{array}{c}\text { Tingkat } \\
\text { kesesuaian } \\
(\%)\end{array}$ \\
\hline \multicolumn{6}{|l|}{ Pelatihan kepada guru Pembina } \\
\hline $\begin{array}{l}\text { UKGS dan dokter kecil tentang } \\
\text { pengetahuan kesehatan gigi dan } \\
\text { mu lut secara terintegrasi }\end{array}$ & 4.68 & $\begin{array}{l}\text { Sangat } \\
\text { Penting }\end{array}$ & 4.05 & Puas & 86.57 \\
\hline $\begin{array}{l}\text { Pendidikan kesehatan gigi } \\
\text { dilaksanakan oleh guru pembina } \\
\text { UKGS sesuai dengan kurikulum } \\
\text { yang berlaku }\end{array}$ & 4.55 & $\begin{array}{l}\text { Sangat } \\
\text { Penting }\end{array}$ & 3.88 & Puas & 85.28 \\
\hline $\begin{array}{l}\text { Pencegahan penyakit gigi dan } \\
\text { mu lut dengan melaksanakan } \\
\text { kegiatan sikat gigi bersama }\end{array}$ & 4.66 & $\begin{array}{l}\text { Sangat } \\
\text { Penting }\end{array}$ & 3.66 & Puas & 78.49 \\
\hline $\begin{array}{l}\text { Pengobatan darurat untuk } \\
\text { menghilangkan rasa sakit oleh } \\
\text { guru }\end{array}$ & 4.73 & $\begin{array}{l}\text { Sangat } \\
\text { Penting }\end{array}$ & 3.89 & Puas & 82.41 \\
\hline Rujukan bagi yang memerlukan. & 4.70 & $\begin{array}{l}\text { Sangat } \\
\text { Penting }\end{array}$ & 3.81 & Puas & 80.98 \\
\hline Rata-rata & 4.66 & $\begin{array}{l}\text { Sangat } \\
\text { Penting }\end{array}$ & 3.86 & Puas & 82.73 \\
\hline
\end{tabular}

Selanjutnya nilai rata-rata tingkat kepentingan dan kinerja tersebut dianalisis pada Importance-Performance Matrix, yang mana sumbu x mewakili persepsi sedangkan sumbu y mewakili harapan. Maka didapat hasil berupa gambar sebagai berikut : 


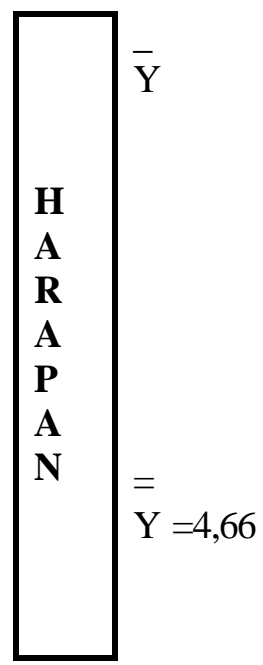

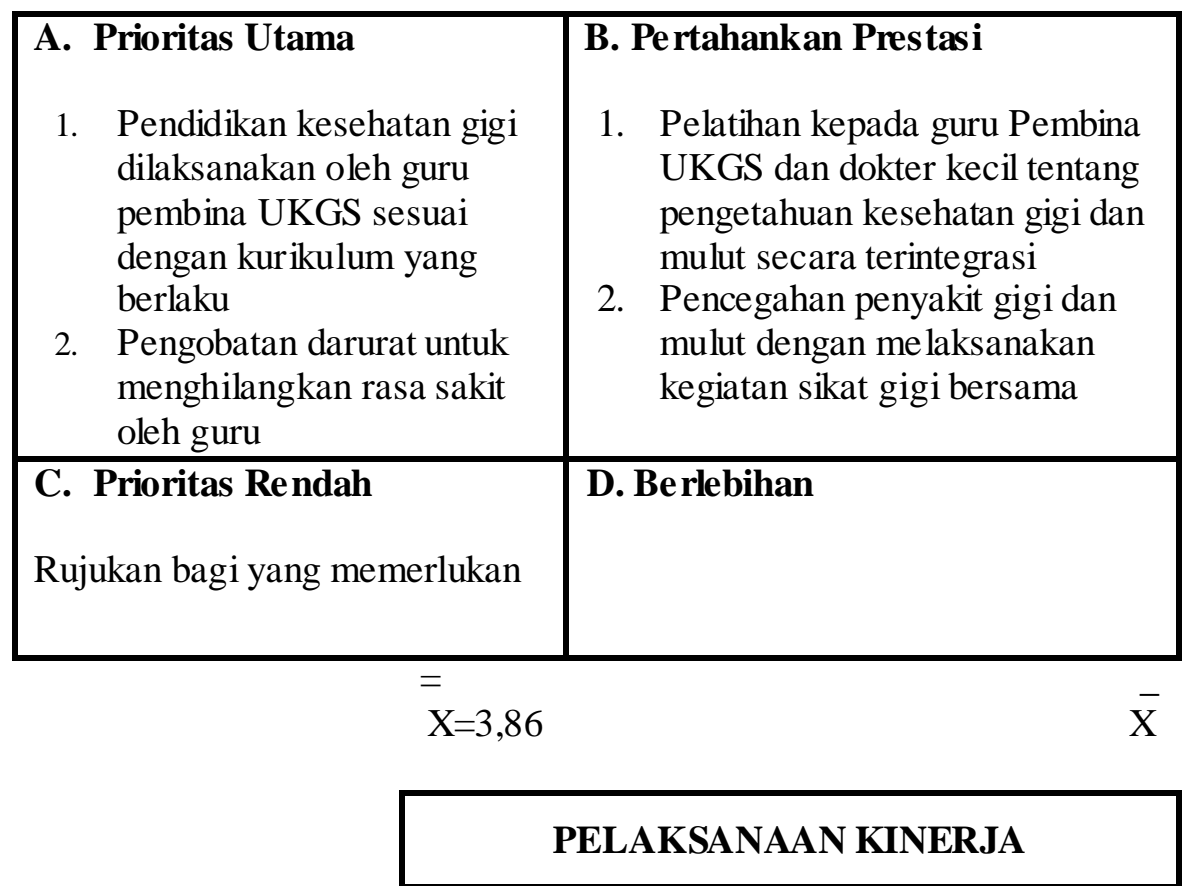

Gambar 2. Diagram Kartesius dari Kualitas Layanan dan Kinerja/Kepuasan Guru UKGS terhadap Layanan Usaha Kesehatan Gigi Sekolah

Berdasarkan hasil perhitungan skor kepuasan Guru UKGS yang telah dilakukan dapat diketahui dua item terbaik yaitu pelatihan kepada guru Pembina UKGS dan dokter kecil tentang pengetahuan kesehatan gigi dan mulut secara terintegrasi, serta pencegahan penyakit gigi dan mulut dengan melaksanakan kegiatan sikat gigi bersama. Dengan analisis Importance Performance Analysis (IPA) maka dapat diketahui masih terdapat hal-hal yang harus ditingkatkan ke depannya, yaitu : pendidikan kesehatan gigi dilaksanakan oleh guru pembina UKGS sesuai dengan kurikulum yang berlaku, serta pengobatan darurat untuk menghilangkan rasa sakit oleh guru.

3. Kinerja Aktual dan Harapan Responden Orangtua Siswa terhadap Layanan Usaha Kesehatan Gigi Sekolah
Pada penelitian ini, responden diminta untuk menilai tingkat kepentingan dan kinerja Usaha Kesehatan Gigi Sekolah yang meliputi : Latihan menggosok gigi, pengajaran formal tentang kesehatan gigi dan mulut, penilaian kebersihan mulut oleh guru melalui pemeriksaan rutin, penyuluhan oleh tenaga kesehatan secara insidental, serta penjaringan (screening) oleh guru dan atau tenaga kesehatan gigi atau pelaksana UKGS untuk menentukan jumlah murid yang perlu perawatan. Maka didapatkan hasil sebagai berikut : 
Tabel 3. Analisis Kepuasan Orangtua Siswa terhadap Layanan Usaha Kesehatan Gigi Sekolah

\begin{tabular}{|l|c|c|c|c|c|}
\hline \multicolumn{1}{|c|}{ Komponen } & $\begin{array}{c}\text { Kualitas } \\
\text { Layanan }\end{array}$ & Kategori & $\begin{array}{c}\text { Tingkat } \\
\text { Ke puasan }\end{array}$ & Kategori & $\begin{array}{c}\text { Tingkat } \\
\text { kesesuaian (\%) }\end{array}$ \\
\hline Latihan menggosok gigi formal tentang & 4.59 & $\begin{array}{c}\text { Sangat } \\
\text { Penting }\end{array}$ & 3.78 & Puas & 82.22 \\
\hline $\begin{array}{l}\text { Pengajaran } \\
\text { kesehatan gigi dan mulut }\end{array}$ & $\begin{array}{c}\text { Sangat } \\
\text { Penting }\end{array}$ & 3.63 & Puas & 79.85 \\
\hline $\begin{array}{l}\text { Penilaian kebersihan mu lut oleh } \\
\text { guru me lalui pemeriksaan rutin }\end{array}$ & 4.58 & $\begin{array}{c}\text { Sangat } \\
\text { Penting }\end{array}$ & 3.80 & Puas & 82.85 \\
\hline $\begin{array}{l}\text { Penyuluhan oleh tenaga kesehatan } \\
\text { secara insidental }\end{array}$ & 4.63 & $\begin{array}{c}\text { Sangat } \\
\text { Penting }\end{array}$ & 3.85 & Puas & 83.13 \\
\hline $\begin{array}{l}\text { Penjaringan (screening) oleh guru } \\
\text { dan atau tenaga kesehatan gigi atau } \\
\text { pelaksana UKGS untuk } \\
\text { menentukan ju mlah murid yang } \\
\text { perlu perawatan. }\end{array}$ & 4.54 & $\begin{array}{c}\text { Sangat } \\
\text { Penting }\end{array}$ & 3.70 & Puas & 81.60 \\
\hline \multicolumn{1}{|c|}{ Rata-rata } & 4.58 & $\begin{array}{c}\text { Sangat } \\
\text { Penting }\end{array}$ & 3.75 & Puas & 81.94 \\
\hline
\end{tabular}

Selanjutnya nilai rata-rata tingkat kepentingan dan kinerja tersebut dianalisis pada Importance-Performance Matrix, yang mana sumbu x mewakili persepsi sedangkan sumbu y mewakili harapan. Maka didapat hasil berupa gambar sebagai berikut :

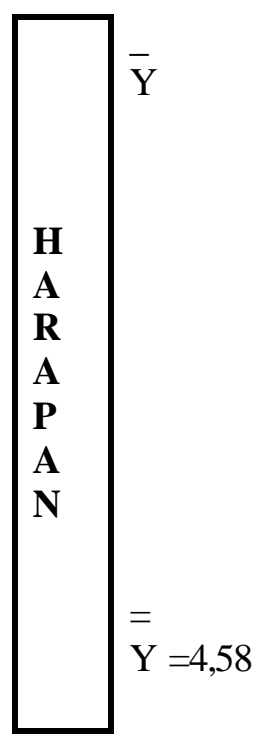

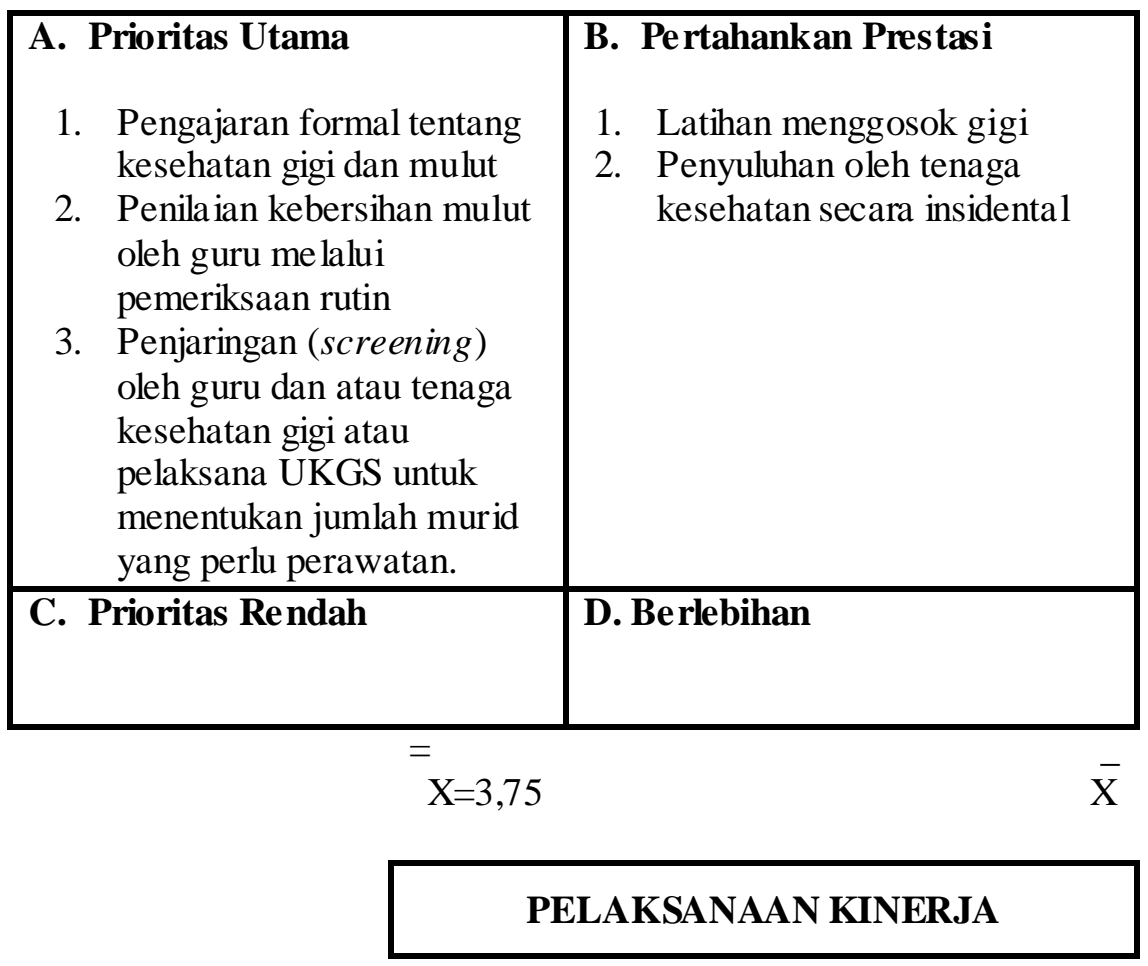

Gambar 3. Diagram Kartesius dari Kualitas Layanan dan Kinerja/Kepuasan Orangtua Siswa terhadap Layanan Usaha Kesehatan Gigi Sekolah

Berdasarkan hasil perhitungan skor kepuasan orangtua siswa yang telah dilakukan dapat diketahui dua item terbaik yaitu latihan menggosok gigi dan penyuluhan oleh tenaga kesehatan secara insidental. Dengan analisis Importance Performance Analysis (IPA) maka dapat diketahui bahwa hal-hal yang masih harus ditingkatkan ke depannya, adalah : pengajaran formal tentang kesehatan gigi dan 
mulut, penilaian kebersihan mulut oleh guru melalui pemeriksaan rutin, penjaringan (screening) oleh guru dan atau tenaga kesehatan gigi atau pelaksana UKGS untuk menentukan jumlah murid yang perlu perawatan.

Teori kepuasan dan ketidakpuasan konsumen terbentuk dari model diskonfirmasi ekspektasi, yaitu menjelaskan bahwa kepuasan atau ketidakpuasaan konsumen merupakan dampak dari perbandingan antara harapan pelanggan sebelum pembelian dengan sesungguhnya yang diperoleh pelanggan dari produk atau jasa tersebut (Butt dan Behman, 2010). Harapan pelanggan saat membeli sebenarnya mempertimbangkan fungsi produk tersebut (product performance). Fungsi produk antara lain : (Ogunnaike dkk, 2014)

1. Produk dapat berfungsi lebih baik dari yang diharapkan, disebut diskonfirmasi positif (positive disconfirmation). Bila hal ini terjadi maka pelanggan akan merasa puas.

2. Produk dapat berfungsi seperti yang diharapkan, disebut konfirmasi sederhana (simple confirmation). Produk tersebut tidak memberi rasa puas dan produk tersebut tidak mengecewakan sehingga pelanggan akan memiliki perasaan netral.

3. Produk dapat berfungsi lebih buruk dari yang diharapkan, disebut diskonfimasi negatif (negatif disconfirmation). Bila hal ini terjadi maka akan menyebabkan kekecewaan, sehingga pelanggan merasa tidak puas.

Pada penelitian ini responden siswa merasa puas atas layanan usaha kesehatan gigi sekolah karena empat item terbaik yaitu: pemberian pengetahuan tentang kesehatan gigi dan mulut, latihan atau demonstrasi cara memelihara kebersihan dan kesehatan gigi dan mulut, sikat gigi bersama di sekolah serta penyuluhan kesehatan gigi dan mulut perorangan. Artinya siswa menganggap layanan usaha kesehatan gigi sekolah dalam dalam empat item tersebut dapat berfungsi lebih baik dari yang diharapkan, atau disebut diskonfirmasi positif (positive disconfirmation) (Mahmood dkk, 2014).

Yang perlu dicatat, kepuasan pelanggan adalah hasil akumulasi dari konsumen atau pelanggan dalam menggunakan produk dan jasa (Tóth dkk, 2014). Oleh karena itu, setiap transaksi atau pengalaman baru, akan memberikan pengaruh terhadap kepuasan pelanggan. Demikian pula, kepuasan pelanggan mempunyai dimensi waktu karena hasil dari akumulasi. Karena itu, siapapun yang terlibat dalam urusan kepuasan pelanggan, ia telah melibatkan diri dalam urusan jangka panjang. Upaya memuaskan pelanggan adalah pengalaman panjang yang tidak mengenal batas akhir (Sahin dan Page, 2014).

Pada penelitian ini responden guru UKGS merasa puas atas layanan Usaha Kesehatan Gigi Sekolah karena dua item terbaik yaitu pelatihan kepada guru Pembina UKGS dan dokter kecil tentang pengetahuan kesehatan gigi dan mulut secara terintegrasi serta pencegahan penyakit gigi dan mulut dengan melaksanakan kegiatan sikat gigi bersama. Maka dapat dikatakan bahwa dua item tersebut di atas mempunyai kualitas jasa yang baik sehingga mampu memenuhi harapan responden, dalam hal ini guru UKGS.

Responden orangtua siswa merasa puas atas layanan Usaha Kesehatan Gigi Sekolah karena dua item terbaik yaitu latihan menggosok gigi untuk siswa dan penyuluhan oleh tenaga kesehatan secara insidental. Maka dapat dikatakan bahwa dua item tersebut di atas mempunyai kualitas jasa yang baik sehingga mampu memenuhi harapan responden, dalam hal ini orangtua siswa.

Kualitas jasa adalah tingkat keunggulan yang diharapkan dan pengendalian atas tingkat keunggulan tersebut untuk memenuhi keinginan pelanggan (Herdlein dkk, 2015). Dengan kata lain ada dua faktor utama yang mempengaruhi kualitas jasa, yaitu expected service dan perceived service (Saif, 2014). 
Apabila jasa yang diterima atau dirasakan (perceived service) sesuai dengan yang diharapkan, maka kualitas jasa dipersepsikan baik dan memuaskan. Jika jasa yang diterima melampaui harapan pelanggan, maka kualitas jasa dipersepsikan sebagai kualitas yang ideal. Sebaliknya jika jasa yang diterima lebih rendah dari pada yang diharapkan, maka kualitas jasa dipersepsikan buruk. Dengan demikian baik tidaknya kualitas jasa tergantung pada kemampuan penyedia jasa dalam memenuhi harapan pelanggannya secara konsisten (Fitri dan Hasan, 2008).

\section{KESIMPULAN}

1. Responden siswa merasa puas atas layanan usaha kesehatan gigi sekolah karena empat item terbaik yaitu : pemberian pengetahuan tentang kesehatan gigi dan mulut, latihan atau demonstrasi cara memelihara kebersihan dan kesehatan gigi dan mulut, sikat gigi bersama di sekolah serta penyuluhan kesehatan gigi dan mulut perorangan.

2. Responden guru UKGS merasa puas atas layanan Usaha Kesehatan Gigi Sekolah karena dua item terbaik yaitu pelatihan kepada guru Pembina UKGS dan dokter kecil tentang pengetahuan kesehatan gigi dan mulut secara terintegrasi serta pencegahan penyakit gigi dan mulut dengan melaksanakan kegiatan sikat gigi bersama.

3. Responden orangtua siswa merasa puas atas layanan Usaha Kesehatan Gigi Sekolah karena dua item terbaik yaitu latihan menggosok gigi untuk siswa dan penyuluhan oleh tenaga kesehatan secara insidental.

\section{DAFTAR PUSTAKA}

Archambault LZ. 2008. Measuring Service Performance, Student Satisfaction and its Impact on Student Retention in Private, Post-Secondary Institutions. EDU-COM Int Conf Sustain High Educ Dir Chang [Internet]. 2008;(November):19-21. http://ro.ecu.edu.au/ceducom/2.

Butt BZ, Rehman KU, 2010. A study examining the students satisfaction in higher education. Procedia - Soc Behav Sci [Internet]. 2010;2(2):5446-50.

http://dx.doi.org/10.1016/j.sbspro.201 $\underline{0.03 .888 .}$.

Fitri H, Hasan A, 2008. Service Quality and Student Satisfaction: A Case Study at Private Higher Education Institutions. Int Bus Res [Internet]. 2008;1(3):163-75.

http://ccsenet.org/journal/index.php/i $\underline{\mathrm{br} /}$

Herdlein R, Zurner E, 2015. Student Satisfaction, Needs, and Learning Outcomes: A Case Study Approach at a European University. SAGE Open [Internet]. 2015;5(2). http://sgo. sagepub.com/lookup/doi/10 $.1177 / 2158244015580373$.

Kemenkes RI, 2013. Riset Kesehatan Dasar Tahun 2013, Jakarta : Badan Penelitian dan Pengembangan Kesehatan, Kemenkes RI.

Kemenkes RI, 2012. Pedoman Usaha Kesehatan Gigi Sekolah, Jakarta : Ditjen Bina Upaya Kesehatan, Kemenkes RI.

List BP, 2015. an Exploratory Study of Predictors of Student Satisfaction. 2015;1-7.

Mahmood WN, Ridhuan M, Dangi M, Anuar $\mathrm{K}$, Ali M, 2014. Investigating Students' Satisfaction Level on Implicit Services of Malaysian Public 
Higher Education Institutions. 2014;18(1):41-59.

Ogunnaike OO, Borishade TT, Jeje OE, 2014. Customer Relationship Management Approach and Student Satisfaction in Higher Education Marketing. J Compet [Internet]. 2014;6(3):49-62.

http://www.cjournal.cz/index.php?hid =clanek\&cid=175.

Pratiwi, DA, Setyawan H, Udiyono A, 2016. Gambaran Pelaksanaan Kegiatan Usaha Kesehatan Gigi Sekolah (UKGS) dan Skor Plak Murid (Studi Pada Sekolah Dasar dan Sederajat di Wilayah Kerja Puskesmas Padangsari Kota Semarang), Jurnal Kesehatan Masyarakat (e-Journal) Volume 4, Nomor 4, Oktober 2016 (ISSN: 23563346) http://ejournals1.undip.ac.id/index.php/jkm.

Rubaman UM. 2008. Mengukur Kepuasan Masyarakat Terhadap Pelayanan Pendidikan. J Madani [Internet]. 2008; www.ejournalunisma.net/?i/article/download/206/1 93.

Sahin O, Page, 2014. An Investigation of Student Satisfaction Factors. Quest Journals J Res Bus Manag [Internet]. 2014;2(6):8-12.

www.questjournals.org.

Saif NI, 2014. The Effect of Service Quality on Student Satisfaction: A Field Study for Health Services Administration Students. Int $J$ Humanit Soc Sci. 2014;4(8):172-81.

Tóth ZE, Jónás T, 2014. Enhancing student satisfaction based on course evaluations at budapest university of technology and economics. Acta Polytech Hungarica. 2014;11(6):95112. 